\title{
openheart Low-grade metabolic acidosis as a driver of insulin resistance
}

To cite: DiNicolantonio JJ, O'Keefe JH. Low-grade metabolic acidosis as a driver of insulin resistance. Open Heart 2021;8:e001788. doi:10.1136/ openhrt-2021-001788

Accepted 27 August 2021

Check for updates

(C) Author(s) (or their employer(s)) 2021. Re-use permitted under CC BY-NC. No commercial re-use. See rights and permissions. Published by BMJ.

${ }^{1}$ Department of Preventive Cardiology, Saint Luke's Mid America Heart Institute, Kansas City, Missouri, USA

${ }^{2}$ University of Missouri-Kansas City, Saint Lukes Mid America Heart Institute, Kansas City, Missouri, USA

Correspondence to Dr James J DiNicolantonio; jjdinicol@gmail.com
INTRODUCTION: WHAT IS METABOLIC ACIDOSIS AND HOW DOES IT DEVELOP?

Metabolic acidosis occurs when there is retention of acid in the body which leads to a drop in the acid buffering capacity of the body. However, acid retention can occur even when serum bicarbonate is normal. ${ }^{1}$ There are four mechanisms through which the body can develop metabolic acidosis: (1) increased ingestion of dietary acid, (2) increased production of fixed acid such as in diabetic ketoacidosis, alcoholic ketoacidosis or prolonged fasting, (3) increased loss of base (ie, diarrhoea) and (4) reduced kidney excretion of acid. Additionally, specific medications can cause or contribute to metabolic acidosis.

There are two major types of acid in the body, carbonic acid and non-carbonic acid. Carbonic acid is formed when a bicarbonate molecule combines with a hydrogen ion. Eventually carbonic acid is turned into water and carbon dioxide. Thus, if we create bicarbonate in the body from alkalinity supplied by the diet then we can breathe out the acid without depleting our own bicarbonate levels. Non-carbonic acids are fixed acids and cannot be exhaled via the lungs. They include lactic acid, phosphoric acid, sulfuric acid, uric acid and the ketoacids acetoacetic acid and beta-hydroxybutyric acid. Some of these fixed acids can be excreted in the urine in their free form, however, the urine $\mathrm{pH}$ can only drop to around 4.4 and hence only negligible quantities of strong acids, like sulfuric acid, can be eliminated in its free titratable form. ${ }^{2}$ So, $99 \%$ of the time sulfuric acid must be turned into hydrogen ions and sulfate and then it can be eliminated by the body.

When we eat animal protein high in sulfurcontaining amino acids such as methionine, cysteine and taurine, we form sulfuric acid, which gets broken down into two hydrogen ions and one sulfate molecule. If we consume a large amount of animal protein, this leads to large amounts of hydrogen ions being produced which gets neutralised by citrate or bicarbonate. Thus, consuming large amounts of animal protein depletes our bicarbonate and citrate buffering capacity. This especially can become problematic once we start producing more than $40-70 \mathrm{mEq}$ of acid per day, which typically occurs at a urinary $\mathrm{pH}$ of 6.25-6.5. Thus, if the urinary $\mathrm{pH}$ is 6.5 or less this suggests acid retention and risk for developing low-grade metabolic acidosis. When sulfuric acid is formed in the body the hydrogen ions must be neutralised via bicarbonate. Additionally, the negatively charged sulfate must be eliminated, which requires a positively charged molecule to be excreted out the body. Typically, this means that positively charged minerals like magnesium, calcium, sodium or potassium are eliminated out the urine with the negatively charged sulfate, which tends to deplete the body of minerals.

Sulfuric acid has a molecular structure of $\mathrm{H}_{2} \mathrm{SO}_{4}$. The two hydrogen ions are neutralised by two bicarbonate molecules (or three hydrogen ions can get neutralised by one citrate molecule), which leaves sulfate remaining. Since we cannot breathe out sulfate it must be excreted out the kidneys. However, to maintain electroneutrality, the negatively charged sulfate $\left(\mathrm{SO}^{2-}\right)$ must be combined with a positively charged substance. If the diet contains enough alkaline minerals, such as magnesium, calcium, sodium or potassium, then the sulfate can be excreted with the dietary cations. However, if the diet is lacking these minerals, then the body will lose minerals until the kidneys can increase the production of ammonia to eliminate the sulfate. For example, two positively charged hydrogen ions $(2 \mathrm{H}+)$ are produced in the kidneys to combine with two ammonia molecules (2 NH3) forming $2 \mathrm{NH} 4+$. This provides the $2+$ charge to offset the 2 - charge of sulfate to form neutral ammonium sulfate $\left(\mathrm{NH}_{4} \mathrm{SO}_{4}\right)$ for excretion. 
However, muscle and connective tissue are broken down to form the ammonia in order to eliminate the sulfate. Furthermore, once the kidneys' capacity for acid excretion is reached, then eliminating sulfate by using hydrogen ions and ammonia goes down, necessitating a greater reliance on alkaline minerals. It also takes time for the kidneys to synthesise ammonia to excrete sulfate, thus, alkaline minerals will also be excreted until the kidneys can ramp up the production of ammonia. Thus, acid-base status in the body is a balancing act determined by the overall acid load of the diet, the kidneys' capacity to eliminate acid, the dietary intake of alkaline minerals and bicarbonate-forming substances. In other words, eating a high animal protein diet can eventually lead to problems if the diet does not contain adequate amounts of bicarbonate-forming substances and alkaline minerals.

Consuming a diet high in high animal protein, but insufficient in alkaline minerals and bicarbonate-forming substances can deplete the mineral status of the body, predispose to bone, muscle and connective tissue breakdown and eventually lead to kidney damage. This is why consuming bicarbonate mineral water and/or plant foods and alkaline minerals, in the context of an animal based or omnivorous diet is an important step to maintaining acid-base status of the body. Thus, there is a cost to eating a diet rich in animal protein related to producing more ammonia (which induces muscle, connective tissue and kidney damage), and/or losing more alkaline minerals (via bone breakdown). In the modern diet, the slow acidification of the body mainly occurs from the proportionately high consumption of animal protein and grains compared with the base-supplying fruits and vegetables. Additionally, phosphoric acid-containing beverages (carbonated soft drinks) also contribute to the dietary acid load.

When we consume organic anions found in fruits and vegetables, like citrate, malate and gluconate, they can convert to bicarbonate in the body and accept hydrogen ions for excretion. This is how we preserve our buffering capacity. The more protein we eat, or the more muscle we have, the more acid we can excrete out the urine as ammonium. ${ }^{2}$ Consuming adequate protein and building/maintaining robust muscle is important for health because it helps reduce the risk of sarcopenia, falls and frailty, and creates more muscle and bone reserves to eliminate extra acid. However, there is still a negative impact on the kidneys from the increased production of ammonia to eliminate the hydrogen ions and sulfate coming from animal protein.

Balance studies from 1966 have shown that healthy humans consuming diets that produce $\geq 0.4$ to $1 \mathrm{mEq}$ of acid $/ \mathrm{kg}$ of body weight leads to the retention of acid in the body. ${ }^{3}$ For an average healthy adult, consuming a diet that leads to $40-70 \mathrm{mEq}$ or more of net endogenous acid production will lead to acid retention. ${ }^{3}$ This means that most Americans are consuming diets that will likely result in some acid retention-triggering the production of large amounts of ammonia and other adverse health consequences such as kidney stones, muscle, connective tissue and bone breakdown, high blood pressure, insulin resistance, chronic pain and other health issues. ${ }^{4-6}$ Metabolic acidosis also increases renal plasma flow and glomerular filtration rate in order to increase the excretion of the acid load ${ }^{7-9}$ Similar effects have been observed eating high meat meals or carnivore diets. ${ }^{1011}$ The kidneys can even hypertrophy due to the increased production of ammonia. ${ }^{12}$ Thus, eating a high dietary acid load can be damaging to the kidneys.

\section{METABOLIC ACIDOSIS CAUSES INSULIN RESISTANCE AND METABOLIC SYNDROME}

'...the interstitial fluid $\mathrm{pH}$ in metabolic tissues readily changes and may contribute to the onset of insulin resistance via diminution of insulin affinity to its receptor. ${ }^{, 13}$

There is a decreased buffering capacity in the interstitial fluid compared with the intracellular cytosol and blood. This is due to the fact that the interstitium only has relatively weak $\mathrm{pH}$ buffers, such as bicarbonate and phosphate, whereas blood also has proteins such as haemoglobin and albumin that can bind to hydrogen ions. Thus, the interstitial $\mathrm{pH}$ varies more than the blood. The acidification of the interstitial fluid can reduce insulin binding to the insulin receptor and reduce glucose uptake into the cell. ${ }^{5} 1314$ Indeed, the level of circulating lactate, which suggests acid retention in the cell and interstitium, negatively correlates with the degree of insulin sensitivity in humans. ${ }^{15}{ }^{16}$ Rat studies also show that lower interstitial fluid $\mathrm{pH}$ occurs in ascites and metabolic tissues prior to the development of diabetic symptoms. ${ }^{17}$ Low urinary $\mathrm{pH}$ is also associated with worse insulin resistance. ${ }^{18} 19$ Importantly, in patients with metabolic syndrome, the 24-hour urine $\mathrm{pH}$ is significantly lower than in normal people and negatively correlates to the number of metabolic syndrome abnormalities. ${ }^{19}$ In summary, low-grade metabolic acidosis predisposes to insulin resistance, type 2 diabetes and metabolic syndrome.

Dietary organic weak acids (like citric and acetic acid) from citrus, plums, vinegar, etc dissociate into anions and protons and only the anions are absorbed from the intestinal lumen into the circulation. Therefore, consuming weak organic acids improves the $\mathrm{pH}$-buffering capacity of the body. 513

\section{METABOLIC ACIDOSIS WORSENS GLUCOSE UPTAKE, OXIDATION AND INSULIN RESISTANCE}

'Acidosis, with lowered $\mathrm{pH}$ and 'alkali reserve' of the body fluids, has numerous concomitant secondary effects. These interdependent effects include disturbances in normal activities of enzyme systems that are involved in many phases of carbohydrate and mineral metabolism, inhibition of insulin action, increased catabolism and decreased anabolism in tissues. ${ }^{, 20} \sim$ George M. Guest $e t$ al, 1952

Numerous studies show that the dietary acid load is associated with worsening of insulin sensitivity and an 
increased risk of type 2 diabetes. ${ }^{21-24}$ Lower bicarbonate levels (a marker of low-grade metabolic acidosis) are independently associated with reduced insulin sensitivity. ${ }^{25}$ In healthy participants from the National Health and Nutrition Examination Surveys 1999-2002, individuals with a serum bicarbonate $<22 \mathrm{mmol} / \mathrm{L}$ had a fasting insulin $12.7 \mathrm{pmol} / \mathrm{L}$ higher than those with a level of $>25 \mathrm{mmol} / \mathrm{L}$. The median value for bicarbonate levels was $23 \mathrm{mmol} / \mathrm{L}$, suggesting that most healthy people in the United States have low-grade metabolic acidosis (serum bicarbonate $\leq 24-26 \mathrm{mmol} / \mathrm{L}$ ) ${ }^{25}$ Having a low urinary $\mathrm{pH}$, another marker of low-grade metabolic acidosis, is associated with a higher risk of visceral obesity and metabolic syndrome. ${ }^{18} \mathrm{~A}$ high dietary acid load also increases cortisol, which can cause visceral adiposity and increase blood glucose and blood pressure. ${ }^{26-30}$

Clinical studies show that correcting metabolic acidosis improves insulin sensitivity. ${ }^{31}$ Experimentally inducing metabolic acidosis in humans impairs glucose metabolism and cellular insulin sensitivity. ${ }^{32}$ Acidosis is a potent inhibitor of phosphofructokinase, the rate limiting enzyme in glycolysis. ${ }^{33}$ Furthermore, acidosis reduces the binding of insulin to receptors on adipocytes, ${ }^{3435}$ induces insulin resistance in muscle ${ }^{14}$ and reduces insulin sensitivity in skeletal muscle and fat cells by increasing the production of cortisol. ${ }^{26} \mathrm{~A}$ low $\mathrm{pH}$ stimulates cortisol secretion to increase the plasma clearance of excess hydrogen ions. ${ }^{2728} \mathrm{~A}$ higher dietary acid load is associated with higher cortisol concentrations and/or its urinary markers. ${ }^{29}$ In contrast, alkali supplementation decreases cortisol levels, total adrenal-glucocorticoid secretion and potentially bioactive free glucocorticoids. ${ }^{36} 37$ Thus, metabolic acidosis induces insulin resistance and elevates cortisol levels, whereas correcting acidosis through alkaline therapies improves these markers.

Administration of dietary acid in the form of ammonium chloride to normal rats or mildly acidotic diabetic rats leads to near total loss of insulin responsiveness due to inhibition of the insulin receptor and glycolysis, which is reversed with sodium bicarbonate supplementation. ${ }^{38}$ Adipocyte insulin binding is reduced in ketoacidotic rats and ammonium chloride infusions reduces insulin receptors in adipocytes which is improved with sodium bicarbonate infusions. ${ }^{35}$ Mild metabolic acidosis reduces the binding of insulin to its receptor and downstream intracellular insulin signalling in myoblasts and adipocytes. ${ }^{1453} 39$ The authors of one study concluded, 'Our present study suggests that lowered extracellular $\mathrm{pH}$ conditions may produce the pathogenesis of insulin resistance in skeletal muscle cells. ${ }^{14}$ A consequence of this may be accelerated protein degradation in skeletal muscle. ${ }^{39}$ Additionally, a low $\mathrm{pH}$ decreases the expression of the insulin sensitiser adiponectin, ${ }^{40}$ which is a hormone that improves skeletal muscle insulin sensitivity. ${ }^{26}{ }^{41}$ Therefore, through a reduction in adiponectin and insulin signalling, metabolic acidosis can induce insulin resistance. However, leptin, which is a satiety hormone, which has also been shown to improve or reverse insulin resistance in diabetic ketoacidosis or diet-induced hepatic insulin resistance, may be involved. ${ }^{42-44}$ Leptin secretion is downregulated in adipocytes exposed to a low $\mathrm{pH}$ medium, whereas sodium bicarbonate administration to people with renal-induced acidosis increases serum leptin levels. ${ }^{45} 46$ So, leptin dysregulation may also be caused by acidosis leading to insulin resistance. ${ }^{26}$

One randomised double-blind study in 153 healthy women and men aged 50 years and older gave potassium bicarbonate, sodium bicarbonate or placebo to see if any changes would occur on fasting insulin or glucose. ${ }^{47}$ The study only lasted 84 days but it did not show any significant changes on these markers. Thus, this human clinical study seemingly contradicts the previous studies showing that alkaline therapy improves insulin sensitivity. However, in order for alkaline therapy to work, the patient population must have low-grade metabolic acidosis at baseline, otherwise there is no acidosis to improve on. It is likely that this was a key limitation of the study. For example, the placebo, potassium and sodium bicarbonate groups had a baseline urinary $\mathrm{pH}$ that was only borderline for acid retention (6.3, 6.04 and 6.12, respectively). These urinary $\mathrm{pH}$ levels are also much higher than a urinary $\mathrm{pH}$ of $<5.3$, which is needed for diagnosing metabolic acidosis. Additionally, the placebo group seemingly had less acidosis at baseline vs those given the potassium and sodium bicarbonate as they had a higher urinary $\mathrm{pH}$ (ie, 6.3 vs 6.04 and 6.12 , respectively). In other words, the placebo group appeared to be more alkaline at the start of the study versus the groups given alkaline therapy. These are likely reasons why the study failed to show benefits on fasting glucose or fasting insulin.

Perhaps even more importantly, the authors also noted that their findings may have been due to chance, and that the measurement they used to determine insulin resistance was not very accurate, as noted in the following, '....as indicated by the confidence intervals around our observed differences, it is possible that, due to chance, we failed to detect true and clinically meaningful effects of bicarbonate treatment on our outcomes. Second, HOMA-IR is a relatively crude index of insulin resistance compared with more elaborate methods. ${ }^{47}$ Indeed, using fasting glucose and fasting insulin is not a very good way to measure insulin resistance. In fact, $64 \%$ of people with normal oral glucose tolerance tests have abnormal postprandial insulin assays indicative of insulin resistance or type 2 diabetes. ${ }^{48}$ Thus, future studies need to be done in individuals with varying degrees of metabolic acidosis (low urinary $\mathrm{pH}$, low serum bicarbonate, low urinary citrate, high urinary ammonium) and better markers of insulin resistance, such as postprandial insulin assay or the gold standard glucose clamp technique should be employed. ${ }^{26}$

However, one such study has already been performed. Indeed, when using the hyperglycaemic and euglycaemic clamp technique (the gold standard for measuring insulin resistance), experimentally inducing metabolic acidosis has been proven to induce glucose intolerance. ${ }^{32}$ 
Indeed, metabolic acidosis caused a significant decrease in tissue insulin sensitivity by $32 \%$ and tissue sensitivity to exogenous insulin by $15 \%$. Fasting insulin levels also increased, despite normal glucose concentrations, indicating insulin resistance. These harms occurred when blood $\mathrm{pH}$ decreased from 7.42 to 7.37 , which is still considered a normal blood $\mathrm{pH}$ (7.35-7.45). However, serum bicarbonate decreased from 24 to $19 \mathrm{mEq} / \mathrm{L}$ (below the normal range of bicarbonate, $23-29 \mathrm{mEq} / \mathrm{L}$, indicating low-grade metabolic acidosis). To summarise, human studies have confirmed that inducing low-grade metabolic acidosis induces insulin resistance using the goldstandard glucose clamp techniques and that correcting this metabolic acidosis improves insulin sensitivity. ${ }^{31} 32$

\section{Summary of the effects of acidosis on insulin resistance}

1. Experimentally inducing metabolic acidosis in humans impairs glucose metabolism and cellular insulin sensitivity. ${ }^{32}$

2. Correcting metabolic acidosis in humans improves insulin sensitivity. ${ }^{31}$

3. Metabolic acidosis reduces the binding of insulin to receptors on adipocytes and induces insulin resistance in muscle. ${ }^{143435}$

4. Metabolic acidosis increases the production of cortisol, which reduces insulin sensitivity in skeletal muscle and fat cells. ${ }^{26}$

5. Mild metabolic acidosis reduces the binding of insulin to its receptor and downstream intracellular insulin signalling in myoblasts and adipocytes. ${ }^{14539}$

6. A low $\mathrm{pH}$ decreases the expression of the insulin sensitiser adiponectin ${ }^{40}$ which is a hormone that improves skeletal muscle insulin sensitivity. ${ }^{2641}$

7. Leptin secretion is downregulated in adipocytes exposed to a low $\mathrm{pH}$ medium, whereas sodium bicarbonate administration to people with renal-induced acidosis increases serum leptin levels. ${ }^{45} 46$

\section{Contributors Both authors contributed to the final manuscript.}

Funding The authors have not declared a specific grant for this research from any funding agency in the public, commercial or not-for-profit sectors.

Competing interests JJD is Director of Scientific Affairs at AIDP. JOK is an owner of a nutraceutical company.

Patient consent for publication Not required.

Provenance and peer review Not commissioned; externally peer reviewed.

Open access This is an open access article distributed in accordance with the Creative Commons Attribution Non Commercial (CC BY-NC 4.0) license, which permits others to distribute, remix, adapt, build upon this work non-commercially, and license their derivative works on different terms, provided the original work is properly cited, appropriate credit is given, any changes made indicated, and the use is non-commercial. See: http://creativecommons.org/licenses/by-nc/4.0/.

\section{ORCID iDs}

James J DiNicolantonio http://orcid.org/0000-0002-7888-1528

James H 0'Keefe http://orcid.org/0000-0002-3376-5822

\section{REFERENCES}

1 Nagami GT, Hamm LL. Regulation of acid-base balance in chronic kidney disease. Adv Chronic Kidney Dis 2017;24:274-9.
2 Remer T. Influence of diet on acid-base balance. Semin Dial 2000;13:221-6.

3 Lennon EJ, Lemann J, Litzow JR. The effects of diet and stool composition on the net external acid balance of normal subjects. $J$ Clin Invest 1966;45:1601-7.

4 Vormann J, Goedecke T. Acid-Base homeostasis: latent acidosis as a cause of chronic diseases. Schweizerische Zeitschrift fur GanzheitsMedizin 2006;18:255-66.

5 Marunaka Y. The proposal of molecular mechanisms of weak organic acids intake-induced improvement of insulin resistance in diabetes mellitus via elevation of interstitial fluid $\mathrm{pH}$. Int J Mol Sci 2018;19. doi:10.3390/ijms19103244. [Epub ahead of print: 19 Oct 2018].

6 Osuna-Padilla IA, Leal-Escobar G, Garza-García CA, et al. Dietary acid load: mechanisms and evidence of its health repercussions. Nefrologia 2019;39:343-54.

7 Adeva MM, Souto G. Diet-Induced metabolic acidosis. Clin Nutr 2011;30:416-21.

8 Györke ZS, Sulyok E, Guignard JP. Ammonium chloride metabolic acidosis and the activity of renin-angiotensin-aldosterone system in children. Eur J Pediatr 1991;150:547-9.

9 Sartorius OW, Roemmelt JC, Pitts RF, et al. The renal regulation of acid-base balance in man. IV. The nature of the renal compensations in ammonium chloride acidosis 1. J Clin Invest 1949;28:423-39.

10 Kontessis P, Jones S, Dodds R, et al. Renal, metabolic and hormonal responses to ingestion of animal and vegetable proteins. Kidney Int 1990;38:136-44.

11 de Santo NG, Capasso G, Malnic G, et al. Effect of an acute oral protein load on renal acidification in healthy humans and in patients with chronic renal failure. J Am Soc Nephrol 1997;8:784-92.

12 Garibotto G, Verzola D, Sofia A, et al. Mechanisms of renal ammonia production and protein turnover. Metab Brain Dis 2009;24:159-67.

13 Aoi W, Zou X, Xiao JB. Body fluid pH balance in metabolic health and possible benefits of dietary alkaline foods. . eFood, 2020: 1. 12-23. https://www.atlantis-press.com/journals/efood

14 Hayata $\mathrm{H}$, Miyazaki $\mathrm{H}$, Niisato $\mathrm{N}$, et al. Lowered extracellular $\mathrm{pH}$ is involved in the pathogenesis of skeletal muscle insulin resistance. Biochem Biophys Res Commun 2014;445:170-4.

15 Reaven GM, Hollenbeck C, Jeng CY, et al. Measurement of plasma glucose, free fatty acid, lactate, and insulin for $24 \mathrm{H}$ in patients with NIDDM. Diabetes 1988;37:1020-4.

16 Santos JL, Cataldo LR, Cortés-Rivera C, et al. Plasma lactate and leukocyte mitochondrial DNA copy number as biomarkers of insulin sensitivity in non-diabetic women. J Physiol Biochem 2019;75:285-97.

17 Aoi W, Hosogi S, Niisato N, et al. Improvement of insulin resistance, blood pressure and interstitial $\mathrm{pH}$ in early developmental stage of insulin resistance in OLETF rats by intake of propolis extracts. Biochem Biophys Res Commun 2013;432:650-3.

18 Otsuki M, Kitamura T, Goya K, et al. Association of urine acidification with visceral obesity and the metabolic syndrome. Endocr $J$ 2011;58:363-7.

19 Maalouf NM, Cameron MA, Moe OW, et al. Low urine pH: a novel feature of the metabolic syndrome. Clin J Am Soc Nephrol 2007;2:883-8.

20 Guest GM, Mackler B, KNOWLES HC. Effects of acidosis on insulin action and on carbohydrate and mineral metabolism. Diabetes 1952;1:276-82.

$21 \mathrm{Xu} \mathrm{H}$, Jia T, Huang X, et al. Dietary acid load, insulin sensitivity and risk of type 2 diabetes in community-dwelling older men. Diabetologia 2014;57:1561-8.

22 Kiefte-de Jong JC, Li Y, Chen M, et al. Diet-dependent acid load and type 2 diabetes: pooled results from three prospective cohort studies. Diabetologia 2017;60:270-9.

23 Fagherazzi G, Vilier A, Bonnet F, et al. Dietary acid load and risk of type 2 diabetes: the E3N-EPIC cohort study. Diabetologia 2014;57:313-20.

24 Akter S, Eguchi M, Kuwahara K, et al. High dietary acid load is associated with insulin resistance: the Furukawa nutrition and health study. Clin Nutr 2016;35:453-9.

25 Farwell WR, Taylor EN. Serum bicarbonate, anion gap and insulin resistance in the National health and nutrition examination survey. Diabet Med 2008;25:798-804.

26 Della Guardia L, Thomas MA, Cena H. Insulin sensitivity and glucose homeostasis can be influenced by metabolic acid load. Nutrients 2018;10. doi:10.3390/nu10050618. [Epub ahead of print: 15 May 2018].

27 Hamm LL, Ambühl PM, Alpern RJ. Role of glucocorticoids in acidosis. Am J Kidney Dis 1999;34:960-5.

28 Bailey JL, Mitch WE. Twice-told tales of metabolic acidosis, glucocorticoids, and protein wasting: what do results from rats tell us about patients with kidney disease? Semin Dial 2000;13:227-31. 
29 Esche J, Shi L, Sánchez-Guijo A, et al. Higher diet-dependent renal acid load associates with higher glucocorticoid secretion and potentially bioactive free glucocorticoids in healthy children. Kidney Int 2016;90:325-33.

30 DiNicolantonio JJ, Mehta V, Onkaramurthy N, et al. FructoseInduced inflammation and increased cortisol: a new mechanism for how sugar induces visceral adiposity. Prog Cardiovasc Dis 2018;61:3-9.

31 Bellasi A, Di Micco L, Santoro D, et al. Correction of metabolic acidosis improves insulin resistance in chronic kidney disease. BMC Nephrol 2016;17:158.

32 DeFronzo RA, Beckles AD. Glucose intolerance following chronic metabolic acidosis in man. Am J Physiol 1979;236:E328-34.

33 Relman AS. Metabolic consequences of acid-base disorders. Kidney Int 1972;1:347-59.

34 Igarashi M, Yamatani K, Fukase N, et al. Effect of acidosis on insulin binding and glucose uptake in isolated rat adipocytes. Tohoku J Exp Med 1993;169:205-13.

35 Whittaker J, Cuthbert C, Hammond VA, et al. The effects of metabolic acidosis in vivo on insulin binding to isolated rat adipocytes. Metabolism 1982;31:553-7.

36 Buehlmeier J, Remer T, Frings-Meuthen P, et al. Glucocorticoid activity and metabolism with $\mathrm{NaCl}$-induced low-grade metabolic acidosis and oral alkalization: results of two randomized controlled trials. Endocrine 2016;52:139-47.

37 Maurer M, Riesen W, Muser J, et al. Neutralization of Western diet inhibits bone resorption independently of $\mathrm{K}$ intake and reduces cortisol secretion in humans. Am J Physiol Renal Physiol 2003;284:F32-40.

38 Cuthbert C, Alberti KG. Acidemia and insulin resistance in the diabetic ketoacidotic rat. Metabolism 1978;27:1903-16.
39 Franch HA, Raissi S, Wang X, et al. Acidosis impairs insulin receptor substrate-1-associated phosphoinositide 3-kinase signaling in muscle cells: consequences on proteolysis. Am J Physiol Renal Physiol 2004;287:F700-6.

40 Disthabanchong S, Niticharoenpong K, Radinahamed P, et al. Metabolic acidosis lowers circulating adiponectin through inhibition of adiponectin gene transcription. Nephrol Dial Transplant 2011;26:592-8.

41 Patel SA, Hoehn KL, Lawrence RT, et al. Overexpression of the adiponectin receptor AdipoR1 in rat skeletal muscle amplifies local insulin sensitivity. Endocrinology 2012;153:5231-46.

42 Pocai A, Morgan K, Buettner C, et al. Central leptin acutely reverses diet-induced hepatic insulin resistance. Diabetes 2005;54:3182-9.

43 Perry RJ, Zhang X-M, Zhang D, et al. Leptin reverses diabetes by suppression of the hypothalamic-pituitary-adrenal axis. Nat Med 2014;20:759-63.

44 Perry RJ, Petersen KF, Shulman GI. Pleotropic effects of leptin to reverse insulin resistance and diabetic ketoacidosis. Diabetologia 2016;59:933-7.

45 Zheng F, Qiu X, Yin S, et al. Changes in serum leptin levels in chronic renal failure patients with metabolic acidosis. J Ren Nutr 2001;11:207-11.

46 Teta D, Bevington A, Brown J, et al. Acidosis downregulates leptin production from cultured adipocytes through a glucose transportdependent post-transcriptional mechanism. J Am Soc Nephrol 2003;14:2248-54.

47 Harris SS, Dawson-Hughes B. No effect of bicarbonate treatment on insulin sensitivity and glucose control in non-diabetic older adults. Endocrine 2010;38:221-6.

48 Kraft JR. Detection of Diabetes Mellitus In Situ (Occult Diabetes). Lab Med 1975;6:10-22. 